\title{
Some Observations on the British and German 3G Telecom Auctions
}

\author{
the latest version of this paper, and related material, will be at \\ http://www.paulklemperer.org \\ Paul Klemperer \\ Nuffield College, Oxford University \\ Oxford OX1 1NF \\ England \\ Int Tel: +441865278588 \\ Int Fax: +44 1865278557 \\ email: paul.klemperer@economics.ox.ac.uk \\ This draft: September 2002
}

\begin{abstract}
I suggest explanations for the apparently puzzling bidding in the year 2000 British and German 3G telecom auctions. Relative-performance maximisation may have been important, but the outcome of the British auction seems to have been efficient.

This paper bundles my comments on two papers presented at the December 2001 CES Ifo conference on the telecom auctions. (For those readers new to the subject, I recommend first reading "How (Not) to Run Auctions: the European 3G Telecom Auctions" European Economic Review 2002 and at www.paulklemperer.org and "The Biggest Auction Ever: the Sale of the British 3G Telecom Licenses" Economic Journal 2002 and also at www.paulklemperer.org.)

JEL Nos: D44 (auctions), L96 (telecommunications).

Keywords: Auctions, Telecommunications, Spectrum Auctions, 3G, UMTS, Bidding.

Acknowledgements: I was the principal auction theorist advising the UK government's Radiocommunications Agency, which designed and ran the UK mobile-phone license auction, but the views expressed in this paper are mine alone. I do not intend to suggest that any of the behaviour discussed below violates any applicable rules or laws. I am grateful for helpful comments from Tilman Börgers, Elmar Wolfstetter and the representatives of some of the firms involved in the German auction to whom I showed an earlier draft, and I am especially grateful to Marco Pagnozzi for our collaboration in the study of the 3G auctions, and for his helpful suggestions about these essays.
\end{abstract}




\title{
1. Some observations on the British 3G telecom auction: comments on Börgers and Dustmann
} (2002)

\author{
Abstract \\ I offer an explanation for some of the bidding in the year 2000 British 3G \\ telecom auction, and observe that Börgers' and Dustmann's (2002) results are \\ consistent with the outcome having been efficient.

\section{Some observations on the German 3G telecom auction: comments on Grimm, Riedel and Wolfstetter (2002)}

\begin{abstract}
Grimm, Riedel and Wolfstetter (2002) have developed an intriguing explanation for the apparently puzzling bidding in the year 2000 German 3G telecom auction. These comments on their paper discuss why I do not find their explanation fully satisfactory, and suggest alternative explanations, including a relative-performance-maximising theory. I also comment briefly on issues about several other $3 \mathrm{G}$ auctions.
\end{abstract}

\section{Figure: European 3G mobile spectrum auctions per capita revenues and telecom stock prices}




\title{
Some Observations on the British 3G Telecom Auction: Comments on Börgers and Dustmann*
}

\author{
By Paul Klemperer
}

\section{Contents}

\author{
I. Introduction \\ II. Efficiency of the UK Auction \\ III. BT's Bidding Behavior
}

I offer an explanation for some of the bidding in the year 2000 British $3 G$ telecom auction, and observe that Börgers' and Dustmann's (2002) results are consistent with the outcome having been efficient.

\section{Introduction}

Börgers and Dustmann (2002a), henceforth $\mathrm{BD}$, is a very valuable and insightful paper that is full of useful detail about the actual bidding in the UK $3 G$ auction and will become a key reference for anyone studying it.

As discussed in Klemperer (2002 a,c) and Binmore and Klemperer (2002), the UK auction was one of the most successful of the western European 3G auctions. Indeed in terms of revenue raised per capita it was the most successful of all the auctions, and it is therefore appropriate to examine, as B-D do, whether the auction's outcome was also as efficient as is often claimed. Furthermore, BD draw attention to many previously unnoted features of the bidding in the UK auction which do not fit well with standard theory, and which may have important implications for future auctions.

I have learnt a lot from B-D's analysis. In what follows, I discuss just two issues about which my interpretation is slightly different. ${ }^{1}$

\footnotetext{
* Acknowledgements: I was the principal auction theorist advising the UK govemment's Radiocommunications Agency, which designed and ran the UK mobilephone license auction discussed here, but the views expressed in this paper are mine alone. I do not intend to suggest that any of the behaviour discussed below violates any applicable rules or laws. I am very grateful to Tilman Börgers for useful comments, and to Marco Pagnozzi for our collaboration in the study of the $3 \mathrm{G}$ auctions and his helpful su ggestions about this essay.

${ }^{1}$ I was the principal auction theorist advising the Radiocommunications Agency which designed and ran the UK auction, but the views expressed in this paper are mine alone.
} 
Paul Klemperer

\section{Efficiency of the UK Auction}

B-D's analysis makes clear that an ascending auction like the UK's runs the risk of an at least slightly inefficient outcome arising in some circumstances. However, it also seems clear that the actual outcome of the UK auction was efficient, or very close to efficient, in the sense of maximising the sum of the valuations of the licence holders.

Klaus Schmidt's (2002) excellent comment explains that the evidence from the bidding in the auction itself suggests that the UK auction was probably efficient. Evidence subsequent to the auction supports the same claim. It seems clear after the fact - and especially after the other European auctions - that the four incumbents had the highest valuations, ${ }^{2}$ so were efficient winners. And there is no evidence that any losing entrant had a value for a license that exceeded TIW-Hutchison's. Finally, the evidence subsequent to the auction, as well as from within it (including the interpretation of the bidding offered below), suggests Vodafone had a higher incremental value for a large license than did any other incumbent, and therefore that the allocation of licenses among winners was also correct.

In short, all the available evidence suggests that the UK auction's outcome was efficient in the sense claimed. ${ }^{3}$

\section{BT's Bidding Behavior}

B-D also suggests that some of the behavior they document is very hard to rationalise, but I conjecture that doing sufficient research into the environment in which the auction took place will yield good explanations, as I will illustrate by examining the main "puzzle"-BT's bidding. ${ }^{4}$

BT's bidding was such that the prices bid for the large $(2 \times 15 \mathrm{MHz})$ "B" and small $(2 \times 10 \mathrm{MHz})$ "C", "D", and "E" licences differed by roughly a constant in the early stages of the auction (phase 1 of the auction in B-D's terminology), and then switched to differing by roughly a fixed proportion (fifty per cent of the price level of the small licenses) in the later stages of the auction (phases 2 and 3 in B-D's terminology). ${ }^{5}$ This pattern seems unusual, but reviewing analysts' reports

${ }^{2}$ See van Damme (2002) and Fortis (2000) for evidence and discussion of these value differences. (Indirect evidence is also provided by the fact that only one out of the thirty incumbent bidders in the eight western European ascending auctions failed to win a license---and even this single failure was attributed to collusion or organizational strife within the bidder, rather than to the incumbent having a low value, see Klemperer 2002a).

${ }^{3}$ Cable et al (2001) use stockmarket data to argue that "there is no evidence that the outcome of the auction was anything but efficient".

${ }^{4}$ However, B-D are to be congratulated on having already explained so much; they also looked at evidence from outside the auction to explain behaviour within it.

${ }^{5}$ That BT's behaviour in the later stages of the auction can be described in this way was observed independently, by B-D and myself, after the conference in Munich to which their paper was contributed. The details are reported in B-D's companion paper, Börgers and Dustmann (2002b). 
suggests a clue: some analysts assumed the value of the large license must be $1 \frac{1}{2}$ times the value of a small icense (reflecting an assumption that $1 \frac{1}{2}$ times the amount of spectrum would allow offering $1 \frac{1}{2}$ times the service ${ }^{6}$ ), while several other analysts insisted the large icense was worth a fixed sum more than a small one (reflecting the additional costs - base stations, etc. - required to run the same service with a smaller licence), and it was clearly well understood in the industry that different bidders might make different choices between these two different valuation models.

Of course, if one or more bidders valued the large licence at $1 \frac{1}{2}$ times the value of the small license, this cannot on its own explain the price difference being a fixed proportion of the value of the small license. For example, if BT's private valuations for small and large licences were $£ 4$ billion and $£ 6$ billion, respectively, while Vodafone's were $£ 6$ billion and $£ 9$ billion, respectively, and other bidders were closer to indifferent between small and large icences, then with "straightforward bidding" (in B-D's terminology) the absolute value of the price difference would quickly move to equal $£ 2$ billion (since whenever the price difference was less than $£ 2$ billion, both BT and Vodafone would regard the large license as the best deal, and so would bid on it).?

However, it seems plausible that BT intrinsically valued a large license more than a smaller license by a fixed value that was considerably below $50 \%$ of the final price of a small license. BT may also have become very confident that Vodafone valued a large licence at $50 \%$ more than a small license. (Apart from any information from outside the auction, Vodafone never placed a bid on any icense other than the large license in the auction.) Furthermore, BT may have wished to make Vodfone pay as much as possible for its license ${ }^{8}$ for at least tw o reasons. First, this would reduce Vodafone's budget and so make Vodafone a weaker competitor in subsequent auctions (the British auction was the first of nine western European $3 G$ auctions, and was also followed by others elsewhere in the world). And second, making Vodafone pay more would make "the market" think Vodafone had not done better than BT in the auction. There is anecdotal evidence that BT was very concerned both about the stock-market's perceptions

${ }^{6}$ The technology might actually allow offering slightly more than $1 \frac{1}{2}$ times the service, hence the value ratio might be slightly more than $1 \frac{1}{2}$.

${ }^{7}$ And even if, as I will argue, some of the early bidding was non-serious, the price difference would move to the fixed amount, $£ 2$ billion, as soon as the bidding became serious.

${ }^{8}$ After the auction BT claimed it had deliberately pushed up the price that Vodafone had paid, and this was reported in the press, see Cane and Owen (2000). (At the time, this claim was pooh poohed by auction theorists as implausible, since it was hard to reconcile with the evidence without realising that BT and Vodafone might both have had different valuation models and also have had a reasonably clear idea of the other's valuation model.) 
of its performance, and about the wider market's view of its position relative to Vodafone. Allowing Vodafone to win the larger license at a lower per- $\mathrm{MHz}$ price than BT was paying might suggest BT's managers had got a bad deal. Or it might suggest that BT was not able to make effective use of a larger license in the way that Vodafone could, and hence that BT thought it was in a weak market position, while Vodafone was clearly "number one". ${ }^{9}$ So bidding up the large license's price to $50 \%$ more than the current small license price may have seemed a reasonable risk to take, even given the small chance of ending up winning the large license at hundreds of millions of pounds more than BT valued it at. ${ }^{10}$

Of course, even a small risk of winning the large license might seem to have a significant expected cost. But it was also possible that if BT did end up winning the large license, it might have been able to resell part of it at little or no loss, given that the auction prices would then have established a clear price per $\mathrm{MHz}$. (The possibilities for resale were unclear, but Hutchison did in effect resell a fraction of the licence it won, very shortly after the auction, to KPN and Docomo at almost exactly the price per MHz that BT and Vodafone paid in the auction. ${ }^{11}$ ) And, anyway, observers might not think BT's managers had made a bad decision, even if BT did end up winning (and keeping) the large license for $50 \%$ more than the price of a small license. ${ }^{12}$

This theory, of course, leaves an important question unanswered. Why did BT not push up the price of the large license in the early stages of the auction? One reason is that much of the bidding in the early stages of the contest, when it was clear that there was no realistic chance of the auction ending very quickly (BD's phase 1) does not seem to have been very serious..$^{13}$ In fact, some bids were probably slightly frivolous, or designed to attract media attention. For example,

9 Klemperer (2002c) and Abbink et al (2002) discuss the importance of bidders' concerns about relative performance in two other auctions in which BT's and Vodafone's subsidiaries both competed, the German 3G auction and the previous year's German DCS-1800 spectrum auction. (Strictly, Vodafone was not involved in the earlier auction but Mannesman, which was a subsidiary of Vodafone by the time of the UK auction, did compete in the earlier auction.)

10 If BT was correct in its assessment that Vodafone's valuation of a large licence was (at least) $50 \%$ more than that for a small license, the (only) risk that BT faced was that Vodafone would quit the auction altogether. But this outcome was completely implausible, since it would imply that Vodafone's valuation for a small license was below that of Orange and One-2-One (which were both weaker incumbents) and at least one new entrant. The real risk would have been that BT had misjudged Vodafone's valuation difference between the licenses, and BT perhaps knew this risk was small.

11 The UK Government now seems likely to make resale relatively easy, but this was unclear at the time of the auction, and actual resale of part of a license may in any case be unattractive since bringing a new competitor into the industry makes the remaining spectrum less valuable. Bringing new partners into a joint-venture as Hutchison did therefore seems the most relevant form of resale.

12 Of course, the arguments of this paragraph are in effect postulating that there may have been important common-value elements to valuations. Note that with common value elements it is plausible that the large license might be worth a fixed amount (say $£ 500$ million $-£ 1$ billion) more than a small license at low prices, but a constant fraction (say $150 \%$ ) of the small license at large prices.

${ }^{13}$ Four bidders have informally confirmed this. 
One-2-One raised its bid by slightly more than the minimum required in round 76 to bid $£ 1,212,100,000 !^{14}$ And BT did start pushing up the price difference between the large and small licences in round 99 when there were still 9 bidders left (so 4 more dropouts were still required to end the auction), and did not then stop pushing up the price difference until round 112 when the large license was more than $50 \%$ (and more than $£ 1 \frac{1}{2}$ billion) more expensive than the small icenses.

A more serious reason why BT did not push up the price difference earlier is that BT may not have wanted to influence other bidders too early to think that license values were very high (since these other bidders might need time to adjust their views, and get extra money approved by their Boards, etc.). For example, if BT's valuation for a small license was $£ 5$ billion, it might have been confident that Vodafone's value exceeded $£ 4$ billion for a small license, and therefore that Vodafone would pay at least $£ 2$ billion more for a large license. But pushing the price difference up to $£ 2$ billion immediately would have sent a very clear signal about what the ultimate prices might be at a time at which the auction prices for the smaller licences were still very low, and this could only have been damaging to BT's interests.

A final possible reason why BT did not push up the price difference early on is that BT may not have become confident that Vodafone's valuation of the large license was $1 \frac{1}{2}$ times its valuation of the small license until later in the auction.

Most likely BT thought that the early bidding was probably not very important but that its best strategy was to roughly mimic what straightforward bidding would have been if it had had low valuations and a correspondingly low difference in valuations. Certainly this is consistent $w$ ith the evidence..$^{15}$

So it seems possible to give a reasonable explanation for BT's bidding. Of course, this may not be the only possible explanation. ${ }^{16}$ How ever, the moral is that understanding bidding in auctions often requires knowing a lot of real-world detail about the players and the context in which they are operating. Facts from outside the bidding itself - in this case knowing the differing valuation models that different analysts used - may be the key to explaining behaviour. In understanding auctions, as well as in designing them, "the devil is in the details". 17

${ }^{14}$ Additional 1's and 2's were ruled out, because all bids were required to be multiples of $£ 100,000$.

${ }^{15}$ Although Vodafone only bid on the large license, it is very plausible that Vodafone was following a similar strategy, but mimicking a bidder with slightly less low valuations.

${ }^{16}$ For example, there may have been much stronger common-value components to valuations than usually assumed.

${ }^{17}$ See Klemperer $(2002 \mathrm{a}, \mathrm{b}, \mathrm{d})$ for more discussion of the importance of understanding the wider context, and of apparently small details, in auction design. 
Paul Klemperer

\section{Summary}

I offer an explanation for some of the bidding in the year 2000 British 3G telecom auction, and observe that Börgers' and Dustmann's (2002) results are consistent with the outcome having been efficient. 


\section{References}

Abbink, K., B. Irlenbusch, B. Rockenbach, A. Sadrieh, and R. Selten (2002) The behavioural approach to the strategic analysis of spectrum auctions: the case of the German DCS -1800 auction, Working Paper, Universities of Nottingham, Erfurt, Tilburg, and Bonn.

Binmore, K. and P. Klemperer(2002), The Biggest Auction Ever: the Sale of the British 3G Telecom Licences, Economic Journal 112 (478), C74-C96, and reproduced with fewer typos at www.paulklemperer.org.

Börgers, T. and C. Dustmann (2002a), Rationalizing the UMTS Spectrum Bids: The Case of the UK Auction, ifo Studien 48 (1),

Börgers, T. and C. Dustmann (2002b), Strange Bids: Bidding Behaviour in the United Kingdom's Third Generation Spectrum Auction, Working Paper, University College London.

Cable, J., A. Henley, and K. Holland (2001), "Pot of gold or winner's curse"'? An event study of the auctions of $3 \mathrm{G}$ mobile telephone licences in the UK, Working Paper, School of Management and Business, University of Wales, Aberyst wyth.

Cane, A. and D. Owen (2000), The UK Cellular Phone Auction, Financial Times, London 28 April, 23.

Fortis Bank(2000), The UMTSReport, Brussels.

Klemperer, P. (2002a), How (Not) to Run Auctions: the European 3G Telecom Auctions, European Economic Review 46 (4-5), 829--845.

Klemperer, P.(2002b), Using and Abusing Economic Theory, 2002 Marshall Lecture to the European Economic Association, forthcoming at www.paulklemperer.org.

Klemperer, $P$. (2002c), Some observations on the German 3G telecom auction: comments on Grimm, Riedel and Wolfstetter, ifo Studien 48 (1), and at www.paulklemperer.org.

Klemperer, P. (2002d), What Really Matters In Auction Design, Journal of Economic Perspectives 16 (1), 169-189.

Schmidt, K. (2002), Efficiency of the British UMTS Auction: A Comment on Börgers and Dustmann, ifo Studien 48 (1),

van Damme, E. (2002), The European UMTS Auctions, European Economic Review 45(45), $846-858$. 


\title{
Some Observations on the German 3G Telecom Auction: Comments on Grimm, Riedel and Wolfstetter*
}

\author{
By Paul Klemperer
}

\section{Contents}

\author{
I. Introduction \\ II. The German Auction \\ III. GRW's Analysis of the German Auction \\ IV. What Actually Happened in the German Auction? \\ V. A Relative-performance-maximising Theory of the German Auction \\ VI. The Austrian and Swiss Auctions \\ VII. The Importance of Entry, and the UK Auction
}

Grimm, Riedel and Wolfstetter (2002) have developed an intriguing explanation for the apparently puzzling bidding in the year 2000 German 3G telecom auction. These comments on their paper discuss why I do not find their explanation fully satisfactory, and suggest alternative explanations, including a relativeperformance-maximising theory. I also comment briefly on issues about several other $3 G$ auctions.

\section{Introduction}

The German 3G spectrum auction was undoubtedly a success from the government's viewpoint. Indeed, it was probably one of only three successes among the nine western European $3 G$ auctions. The measure of success most commonly used is total revenue raised per capita, with some adjustments for the level of the telecoms stock index as a reflection of sentiment towards 3G's

* Acknowledgements: I was the principal auction theorist advising the UK govemment's Radiocommunications Agency, which designed and ran the UK mobilephone license auction, but the views expressed in this paper are mine alone. I do not intend to suggest that any of the behaviour discussed below violates any applicable rules or laws. I am grateful for comments from Elmar Wolfstetterand the representatives of the firms involved in the German auction to whom I showed an earlier draft, and I am also very gra teful to Marco Pagnozzi for our collaboration in the study of the 3G auctions, and for his helpful sugge stions about this essay. 
prospects. ${ }^{1}$ (We assume governments have no ability to time the market, and therefore deserve neither credit nor blame for selling when market sentiment is unusually positive or negative.) Based on this, the figure suggests the UK, German and Danish auctions were successes, while the Netherlands, Austrian and Swiss auctions were the biggest failures.

Figure

European 2000-2001 3G Mobile Spectrum Auctions

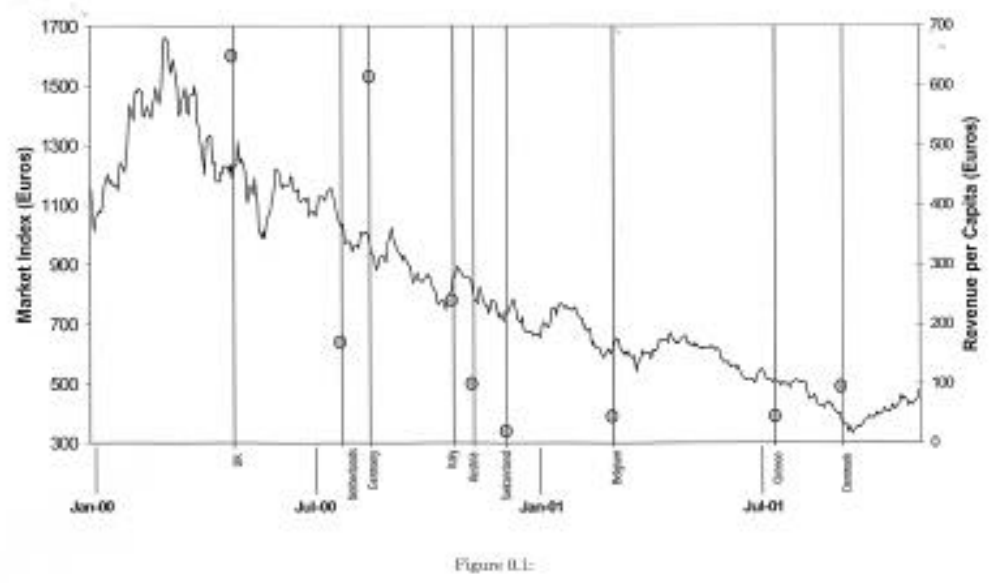

Note: Per-capita revenues, by country o (right-hand scale),

(auctions are shown on the dates at which they finished),

Dow Jones European Telecom Stock Price Index (left-hand scale).

To be sure, the figure flatters larger countries (especially Germany, conversely it underrates tiny Denmark), flatters centrally located countries (Germany, again, and also Austria and Switzerland), flatters countries with lightly regulated telecom industries (Germany, again, among others) - since larger, centrally located, lightly regulated markets are worth more - but it also ignores the fact that Germany and Austria sold more licences than other countries, reducing the total profitability of those markets. However, the more systematic discussion of the relative performance of the different auctions in Klemperer (2002a) comes to very similar conclusions.

${ }^{1}$ Although efficiency was generally the primary objective, there is no evidence that efficiency differed much across the different countries' auctions. Hence the focus on revenues. 
So, since the German auction was both a success and was of a novel and complex design, it clearly deserves study, and Grimm, Riedel and Wolfstetter's (2002) paper (henceforth GRW) would be welcome for that reason alone; their paper gives very valuable detail about the auction and will be a key reference for anyone studying it. But more than that, the paper is extremely interesting and makes acute observations about both the German and other $3 \mathrm{G}$ auctions.

I have learned a lot from the paper, and agree with much of it. However, these comments will naturally focus on the disagreements. Section II summarises why I think GRW's explanation of the bidding in the German auction is not fully satisfactory, and Section III develops this point more fully (the latter section can be omitted by readers who do not want too much detail). Section IV suggests other explanations for the bidding, and Section $\mathrm{V}$ develops a relative performance maximising theory for it. Sections VI and VII briefly comment on some other 3G auctions, and stress (as GRW also do) the importance of attracting entry into an auction.

\section{The German Auction}

In particular, I disagree with GRW's central claim that their model, as it stands, rationalises the behaviour of the two strongest bidders - T-Mobil and Mannesman, or "T" and "M", in GRW's terminology. ${ }^{2}$ These bidders initially pushed up the price in the hope of driving out the sixh-strongest bidder, "bidder 6" in GRW's terminology, but then gave up pushing the price up so that the auction did actually end with six winners but at a much higher price than was necessary to end the auction with this number of winners. This seems bizarre. To put the point simply, consider T's and M's decision about whether to end the auction with six winners at some given price, or whether to push the price up further. Raising the per-block price by 1 euro costs T and M 2 euros each, since they would each win 2 blocks in a six-w inner outcome. Their gain is the probability that bidder 6 quits, times their benefit from bidder 6 quitting. If it is worthwhile for $\mathrm{T}$ and $\mathrm{M}$ to push the price up in one round, but to stop pushing the price up in the next round, then the perceived probability of bidder 6 quitting in the next round must be both low, and also lower than it was in the last round. However, most observers thought the probability of bidder 6 quitting in the next round, conditional on not having previously quit, was high and increasing around the time $\mathrm{T}$ and $\mathrm{M}$ ended the auction (when per capita price levels were approaching those achieved in the UK) and was much lower earlier (a six-player conclusion for the auction became possible at $55 \%$ of the UK price lev els). So any rationalisation of $\mathrm{T}$ and M's behaviour must explain this apparently irrational behaviour of theirs. But GRW's model sidesteps this basic issue, as I now explain:

\footnotetext{
2 T-Mobil and Mannesman were subsidiaries of Deutsche Telekom and Vodafone, re spectively.
} 


\section{GRW's Analysis of the German Auction}

(This section can be omitted by reader $s$ who do not want too much detail.)

To understand GRW's argument - and why I believe it is incomplete in this context - consider the preferences of either one of the two strong bidders, $M$ and $\mathrm{T}$. At any point of time, it would like to end the auction only $\mathrm{f}$ it prefers this to waiting until the price has risen a small further amount, $\Delta$ price, before the auction ends.

The gain from waiting is the probability, $\rho_{6}$, that bidder 6 will quit in the price interval, $\Delta$ price times the value of driving bidder 6 out. This value is itself the benefit, $\beta$, of winning a third block, including the benefits from excluding bidder 6 from the industry (leading to a more concentrated, and hence more profitable, market), less the current price of buying an additional block. That is, the total gain from waiting equals $\rho_{6}[\beta-$ price $]$.

The cost of waiting is the extra price, $\Delta$ price, paid on the two units that the bidder will win anyway, i.e., 2( $\Delta$ price). That is, the bidder would prefer to plan to end the auction if a further price rise of $\Delta$ price fails to drive out bidder 6 , rather than end it now if

$$
\rho_{6}[\beta-\text { price }]>2[\Delta \text { price }]
$$

The bidder would prefer to end the auction now if

$$
\rho_{6}[\beta-\text { price }]<2[\Delta \text { price }] \text {. }
$$

In GRW's model, bidder 6's value can only take one of two possible values, $v_{6}^{\prime}$ (strong type) and $v_{6}$ (weak type), and the auction cannot be ended before price $p\left(<v_{6}\right)$, so the only conceivably sensible strategies for the strong bidders are

a) to end the auction as soon as possible at $p$, or

b) to push the price up a further $\Delta$ price $=v_{6}-p$ to $v_{6}$ to drive out the weaker type of bidder 6 , but then to end the auction, or

c) to push the price up further still, by an additional $\Delta p r i c e=v_{6}^{\prime}-v_{6}$ more to $v_{6}^{\prime}$, to drive out both types of bidder 6 .

The observed behaviour in the actual auction corresponded to case b) of GRW's model.

The condition for b) to be preferred to a) is the appropriate version of (1) or equivalently is GRW's equation (9). ${ }^{3}$ The condition for b) to be preferred to c) is

\footnotetext{
${ }^{3}$ In GRW's notation, $\beta=v_{13}+b$ for the case of successfully driving out bidder 6 at price $v_{6}$.
} 
the appropriate version of (2), or equivalent ly GRW's equation (6). ${ }^{4}$ So these are the key conditions in GRW's Theorem. ${ }^{5}$ If (6) holds there is an equilibrium in which outcome b) arises. (If (6) fails, both strong bidders prefer $c$ ), and either can unilaterally implement it.) If (9) holds, the equilibrium is unique. If (9) fails, outcome b) can still be an equilibrium of the model if (6) holds, since neither strong bidder can unilaterally end the auction, but the equilibrium is neither unique, nor plausible. ${ }^{6}$ So for the observed play to correspond to a pausible equilibrium of GRW's model, both (9) and (6) are required. ${ }^{7}$

Noting that (9) and (6) are just my equations (1) and (2) suggests why GRW's theory seems unlikely to describe reality. Of course, (9) and (6) correspond to (1) and (2) evaluated at different values of $\rho_{6}, \beta$, price and $\Delta$ price, reflecting the different stages of the game at which (9) and (6) are computed. So the observed play can correspond to an equilibrium of GRW's model. But this requires that $\left[\rho_{6} /(\Delta\right.$ price $\left.)\right]$ not be too much lower when the strong bidders could first have ended the auction (when (1) must be satisfied) than at the actual end of the auction (when (2) must be satisfied). ${ }^{8}$

Furthermore, the tension between conditions (9) and (6) is more severe when the game is generalised to many small stages since the values of $\left[\rho_{6} /(\Delta\right.$ price $\left.)\right]$, $\beta$, and priceto be substituted into (1) and (2) cannot then vary much between stages, and related conditions must then hold at all the stages - an issue that GRW do not address. ${ }^{9}$ In particular, (1) must hold just before the auction ends,

${ }^{4}$ In GRW's notation, $\beta=v_{13}^{\prime}+b$ for the case of driving out bidder 6 at price $v_{6}^{\prime}$, but $\rho_{6}=1$ in GRW's model at stage $\left.c\right)$.

${ }^{5}$ GRW rename (6) as " $\Delta_{p r}^{2} \leq 0 "$ in their statement of Theorem 1.

${ }^{6}$ This equilibrium is not plausible if (9) fails because in this equilibrium both strong players prefer outcome a) to outcome b), but both follow the strategy corresponding to b) because each expects the other to do this. This logic can only hold in the two-stage model: with more stages, each strong player would know that if it followed the strategy corresponding to a), then the other strong player would follow just one round of the auction later (if (9) fails) - that is, the players could trivially coordinate on strategy a) in the actual multi-round auction, which eliminates this equilibrium. This equilibrium is, of course, also Pareto dominated by the more natural equilibrium for the players in GRW's two-stage model, and GRW also eliminate this equilibrium in their limited extension to multiple rounds (see note 9). However, an equilibrium of this kind becomes more plausible if $\mathrm{M}$ and $\mathrm{T}$ are each uncertain that its rival shares its assessment of the parameters, or are uncertain about the rival's objectives - see section V.

${ }^{7} \mathrm{GRW}$ note that Theorem 1 requires other conditions too.

${ }^{8}$ It does not seem likely that ( $\beta$ - price) ever became very small because $\beta$ includes both the value of a third block to a strong bidder and the value, $b$ in GRW's terminology, of excluding bidder 6 from the industry, leading to a more concentrated and hence more profitable market. Therefore, $\beta$ must be greater than $p_{2}+b$, where $p_{2}$ is the expected maximum of the value of a fourth block to a strong bidder and a third block to a less strong bidder. And, as GRW point out, $p_{2}$ must itself be quite high for the GRW equilibrium to make sense - the logic of GRW's equilibrium requires $p_{2}$ to at least equal the final Geman auction price. (The very limited anecdotal evidence su ggests that $p_{2}$ might have been, very roughly, in the region of the final German auction price.)

${ }^{9} \mathrm{GRW}$ do briefly consider extending their model to many rounds of bidding, but when they do this they maintain the extreme assumption that bidder 6's valuation can take only 
and (2) must hold at the price at which the auction ends. So if, as was the case in the actual auction, the price is changing only slowly betw een rounds, it is required that $\left[\rho_{6} /(\Delta p r i c e)\right]$ is falling (or at least not much increasing) at the end of the auction.

So, summarising the two previous paragraphs, GRW's equilibrium requires that, at the end of the auction, the probability of bidder 6 quitting conditional on not yet having done so is both not much increasing, and not much larger than at the lower prices at which the strong bidders could earlier, if they had both wished, have ended the auction.

And these two conditions seem implausible. A six-player conclusion to the auction became possible when Debitel quit at prices that were just $55 \%$ of the final UK prices (per capita). ${ }^{10}$ The German auction atually finished at $94 \%$ of the final UK prices. The weakest of the six remaining bidders was generally thought to be either Mobilcom or "Group 3G", the joint-venture between Telef onica and Sonera, so $\rho_{6}$ represents the probability that one of these would quit in the next round, conditional on their not yet having quit. But Telefonica and Mobilcom had quit the UK auction when the price levels had reached $94 \%$ and $100 \%$ of the final UK price level, respectively. ${ }^{11}$ Mobilcom (at least) had made public statements that suggested that it was likely it would bid as far as it had in the UK' ${ }^{12}$, and outside observers also thought that these bidders would probably go a lot further than $55 \%$ of the UK auction price, but might quit at around the final UK price levels. Certainly, most plausible distributions of valuations implied that at the end of the auction the probability of bidder 6 quitting was both much higher than earlier, and increasing, and either of these implications is sufficient to rule out GRW's equilibrium. ${ }^{13}$

two possible values, $v_{6}$ and $v_{6}^{\prime}$. Thus in their exten sion there is no possibility of bidder 6 quitting before $v_{6}$, or between $v_{6}$ and $v_{6}^{\prime}$, so the additional rounds of bidding are mostly irrelevant and (1) and (2) are relevant only at the same points at which they matter in the two-stage game, i.e., GRW's conditions (9) and (6) suffice as before. In a proper manyround extension of GRW's game in which it is also recognised that bidder 6's valuation is not restricted to just two possible values, conditions related to (1) or (2) must hold at each round of the game. (One difference that arises even in GRW's simplified many-round version is that (9) and (6) are both required for GRW's result to be an equilibrium.)

10 Ending the auction at these prices would have required the cooperation of all six bidders, but this could probably have been obtained. And even if this seemed hard, $M$ and $T$ could together have ended the auction once the other four bidders had stopped bidding for three blocks; none of the other bidders had high bids for three blocks beyond round 136 when the prices were $70 \%$ of the final UK price, and all could be proved to have lost eligibility for three blocks shortly thereafter.

${ }^{11}$ Mobilcom was in large part owned by France Telecom which was also part owner of NTL Mobile, the last bidder to quit the UK auction.

12 It may be objected that such statements were cheap talk. But following through on them may be necessary to maintain management credibility, they probably reflected an availability of fnance, and - what matters - they seemed credible to observers at the time.

${ }^{13}$ Although GRW argue (in the last paragraph of their Section V) that it was reaso nable to expect that bidder 6 might quit at some point before the final German auction price, they fail to consider the crucial questions about the relative likelihoods of bidder 6 quitting at $a$ very low price, or at close to the final UK prices 
In brief, GRW's equilibrium requires, roughly, that the strong bidders thought it relatively likely that Mobilcom or Group $3 \mathrm{G}$ would quit while prices were well below UK levels but then, having seen that Mobilcom and Group 3G did not quit at such low prices, the strong bidders thought it both relatively unlikely, and increasingly unlikely, that they would quit while prices were close to UK levels. And this seems unreasonable.

\section{What Actually Happened in the German Auction?}

Whilst no-one can be certain, it seems that other factors are required to explain the behaviour of T-Mobil and Mannesman in the German auction. Some of these factors are discussed in Klemperer $(2002 a, b) .{ }^{14}$

They include the complexity of the rules and the opacity of the information available to bidders about others' bids, which made it hard for bidders to figure out optimal strategies (T may simply have made a mistake in failing to heed M's signal suggesting that they both reduce demand early on) or to understand their rivals' thinking. Klemperer (2002b) stresses the apparent lack of trust and understanding between the two strong bidders, and discusses why this mistrust might have arisen.

Furthermore, the strong bidders may not simply have been maximising expected profits. $\mathrm{M}$ and $\mathrm{T}$ may have focused more on their performances relative to each other, as might be rational behaviour for managers who had private career concerns, or were concerned that their firm seemed wellmanaged and deserving of further investment, etc. Relative performance concerns may explain the auction's outcome, especially in conjunction with the mistrust between the bidders, as we explain in more detail in the next section.

Other contributory factors to T's behaviour that have been suggested include that $T$ felt pressured by the stockmarket's response to the rising auction prices (and that $T$ had not fully anticipated this), and even that T's objectives were affected by the fact that it was majority owned by the German government.

\section{A Relative-performance-maximising Theory of the German Auction}

GRW explain that if, for example, $M$ reduced demand to 2 blocks while $T$ did not, and $T$ then won 3 blocks by driving out bidder 6 , there would then have been a second auction for the remaining block which would most probably have

14 Ewerhart and Moldovanu (2001) make interesting points about the Geman design but in a model in which there is only a single strong bidder, so they cannot address why initially both strong bidders pushed up the price, and then both stopped doing so. Also they do not model the second auction that would have taken place if just one strong bidder had pushed up price and subsequently driven a weak bidder out, and this possible second auction may have played an important role in behaviour in the main auction, as we discuss in section $\mathrm{V}$. 
been won by $\mathrm{M}$ at an expected price $p_{2}$ (in GRW's terminology) so both $\mathrm{M}$ and $T$ would have ended with 3 blocks but having paid different prices for them.

Recall also from our discussion above that when prices are still low (e.g., around $55 \%$ of the final UK auction price) the probability of bidder 6 quitting is low, so it probably maximises both firms' expected profits to reduce demand to 2 blocks and end the auction at low prices. However, if one firm, say M, reduces demand while $T$ fails to do so and continues to push the price up, there is some - perhaps small - probability that bidder 6 will be driven out at a price $\tilde{p}<p_{2}$, in which case $T$ and $M$ will both end up with 3 blocks (assuming that $M$ wins the block in the second auction), but $T$ will on average pay less for its blocks than $M$ (since $\mathrm{T}$ pays $3 \tilde{p}$, but $\mathrm{M}$ expects to pay $2 \tilde{p}+p_{2}$ ). Even in this case $\mathrm{T}$ and $\mathrm{M}$ may both be worse off in absolute terms than if $T$ and $M$ had both reduced demand to win 2 blocks at low prices. And because the chance of driving out bidder 6 at a low price is not that high, the more probable result would simply be that $T$ would eventually reduce its own demand to 2 blocks later on, in which case both $\mathrm{T}$ and $\mathrm{M}$ would be much worse off than if they had both reduced demand earlier. But note that $\mathrm{T}$ always mproves its performance relative to $\mathrm{M}$ by failing to reduce demand at prices below $p_{2}$.

Furthermore, even if each firm is actually an ordinary profit maximiser, but each firm expects the other is likely to maximise relative performance, then neither firm will reduce demand first (since being the only firm to reduce demand when prices are low risks paying $2 \tilde{p}+p_{2}$ rather than $\left.3 \tilde{p}\right) \cdot{ }^{15}$

Similarly, when prices are higher (e.g., close to the final UK levels), t may maximise both M's and T's expected profits to push up the price to drive out bidder 6 . But if one of the firms, say $T$, reduces demand to 2 blocks and lets $M$ push up the price on its own to drive out bidder 6 at a price $p^{*}>p_{2}$, then a gain $T$ and $M$ will both end up with 3 blocks (assuming that $T$ wins the block in the second auction) but $T$ will pay less on average for its blocks than $M$ pays (since T expects to pay $2 p^{*}+p_{2}$, but M pays $3 p^{*}$. So T would improve both its relative and its absolute perfor mance if it could reduce demand alone, and $\mathrm{M}$ would then improve its relative performance by reducing demand along with $\mathrm{T}$, even though $M$ might increase its (and T's) absolute profits by continuing to raise price to drive out bidder 6 .

The story told thus far is extreme. True, there is anecdotal evidence that firms' managers cared about relative performance, and concerns about relative performance also seem to have played at least some role in other European 3G auctions (see, for example, Klemperer 2002c). ${ }^{16}$ But $M$ and $T$ were surely not concerned only with relative performance. So one might have expected $\mathrm{M}$ and $\mathrm{T}$ to attempt to coordinate their behaviour to reduce their demands at low prices

\footnotetext{
${ }^{15}$ A similar argument is that if all firms are known to be ordinary profit maximisers, but firms are unsure that their rival has the same estimates of parameters such as $\rho_{6}$, then firms may be unwilling to reduce demand first.

${ }^{16}$ Abbink et al (2002), section 4, provides some evidence that relative-performance issues were important to these bidders in the German DCS-1800 auction.
} 
to maximise both of their absolute profits. Indeed it seems that $\mathrm{M}$ did initially try to signal to $T$ that they should do just this (see GRW and Klemperer 2002a,b). But $T$ could not know whether $M$ was sincere, and the firms apparently mistrusted each other's intentions (see Klemperer 2002b) and, as we have seen, there are very strong relative-performance arguments (it suffices that each feared that the other might maximise relative-performance) why neither was prepared to be the first to reduce demand while prices were still low.

$T$ then reduced demand later when prices were higher, perhaps for relative performance reasons ${ }^{17}$, and/or because this could also improve its absolute performance if $\mathrm{M}$ failed (or was unable) to follow its demand reduction..$^{18,19}$ And once $T$ had reduced demand, there ae several possible reasons why $M$ followed straightaway. First, $M$ had a strong relativeperformance incentive to follow immediately, as explained above. Second, M may have wanted to develop a reputation for co-operative behaviour in which $M$ and $T$ parallel each other's behaviour - a kind of "relative-performance" effect but strictly driven by M's long-run absolute-performance goals (see Klemperer 2002b). Third, M might have been concerned only with its (short-run) absolute performance, but it might all along have taken the view that this would be maximised by $M$ and $T$ both reducing demand, and it might have stuck to this view (i.e., $M$ may have been extremely pessimistic about driving out bidder 6 at low prices and, even though driving out bidder 6 seemed more likely at high prices, remained fairly pessimistic - see Klemperer 2002a); this is consistent with M's early behaviour

${ }^{17}$ It might seem that a firm could protect its relative performance by following a strategy of quitting only if its rival quits when prices are above $p_{2}$. Ho wever, it takes time to be sure the rival has quit (because the auctioneer gave the bidders only limited inform ation about their rivals' bidding), and it also takes time to respond. Fu rthermore, some of the weaker players may have been staying in the auction in the hope of being a winner in a five-firm industry, which would have been the outcome if $M$ and $T$ had successfully driven one of them out - in particular, each of Mobilcom and Group 3G might have hoped that the other (or possibly E-plus or Viag) was the "bidder 6" who might have been driven out. In this case, when one of $\mathrm{M}$ and $\mathrm{T}$ quits bidding for a third block, these weaker players may expect the other of $\mathrm{M}$ and $\mathrm{T}$ to try to follow suit and may therefore try to quit first rather than find themselves stuck as winners in a much-less-profitable six-firm industry. So if ether $\mathrm{M}$ or $\mathrm{T}$ failed to quit first when prices became high, it might have risked being stranded buying a third block at a higher price than its opponent, and achieving a very poor relative-performance.

18 If $T$ thought $M$ was not too concerned with relative performance, $T$ could improve both its relative and absolute performance by reducing demand once the price exceeded $p_{2}$, and free-riding on $\mathrm{M}$ continuing to push price up to drive out bidder 6 . And even if $\mathrm{M}$ was concerned with relative perfomance, there was the possibility that $M$ would have been unable to follow $\mathrm{T}$ (see note 16).

${ }^{19}$ Of course, there may be other reasons, such as $\mathrm{T}$ being influenced by stockmarket pressure or its government ownership (se e section IV). It might be argued that another possibility was that $\beta$ was not in fact that high. However, this seems less likely since $\beta$ must have substantially exceeded $p_{2}$ (see note 8 ) and if $p_{2}$ were low then both firms would have been willing to reduce demand early on for relative-, as well as absolute, performance reasons. 
(signalling $\mathrm{T}$ to reduce demand but not unilaterally reducing demand) if it feared that $\mathrm{T}$ might place a large weight on relative performance.

Of course, there may be other reasons for the observed behaviour in the auction. For example, fear that one's rival has very different perceptions from one's own about the chance of driving out bidder 6 can have similar effects to fear that one's riva is a relativeperformance maximiser ${ }^{20}$, and Klemperer (2002b) emphasises the mistrust and misunderstanding between the bidders. But the point is that the apparently puzzling behaviour can be explained by postulating only a limited concern with relative performance. To explain why $M$ and $T$ failed to reduce demand early on, it suffices that each firm thought its rival put some weight on relative performance; it is not necessary that either firm actually did so, and even the conjectured weights on relative performance need not have been large if firms were also uncertain about their rivals' perceptions about bidder 6's behavior, etc. And not much more concern with relative performance is needed to explain the firms' later behaviour in the auction.

\section{The Austrian and Swiss Auctions}

Turning to other 3G auctions, I disagree with GRW's assertion that the Austrian auction design was superior to the Swiss, except to the extent that the Austrian reserve price was somewhat more realistically chosen than the Swiss reserve. Neither auction attracted more bidders than there were winners, and neither involved any significant bidding. (Although there was a semblance of serious bidding in the Austrian auction, the bidders there were put under considerable pressure from the authorities to continue the bidding, and it was widely believed that the bidding only lasted the few rounds it did in order to create some public perception of genuine competition and reduce the risk of the government changing the rules.) Neither auction achieved more than $11 \%$ more than the eserve price that had been set. The only important difference is that the Swiss reserve price had been set ludicrously low at 20 euros per capita, while the Austrian reserve price, although still far lower than it should have been, was 90 euros per capita. ${ }^{21}$ But revenues in excess of 300 euros per capita should probably have been attainable in both auctions, see Klemperer (2002a). So both of these auctions were failures, and both were intensely embarrassing to their respective governments. Indeed there was no successful European 3G auction after the UK and German auctions until the Danes switched to a sealedbid design. I have discussed all these auctions in more detail in Klemperer (2002a).

\section{The Importance of Entry, and the UK Auction}

\footnotetext{
20 In particular, ether fear can make a bidder unwilling to reduce demand first when prices are low, because of the perceived risk that the rival will not follow. See note 15.

21 Of course, Switzerland sold 4 licences while Austria sold 6, but the Swiss could obviously have used their same design to sell 6 icences if they had preferred that outcome.
} 
Where I do agree very strongly with GRW is on the importance of attracting entry into an auction. ${ }^{22}$ As GRW say, "competition is not a free good" and auctions must be designed with this in mind. However, this does not imply that there is any single best design. Often a sealed-bid design is best for attracting entry, as is suggested by the Danish example in the previous par agraph. But this need not be the case. The UK design was appropriate in its context, because the UK auction was the first $3 G$ auction and was therefore unlikely to suffer from entry problems. (See Klemperer (2002a,b) for more discussion of why being first was so important.) Indeed the UK auction attracted 13 bidders compared with the 7 that entered the German auction. It seems improbable that the German design would have usefully increased competition in the British auction, and the British design had other advantages over the German design ${ }^{23}$, see Binmore and Klemperer (2002) and Klemperer (2002a) (though my view may be coloured by my having been the principal auction theorist for the UK auction $\left.{ }^{24}\right)$. In another context, when Peter Cramton, Eric Maskin and I advised on the UK's 2002 auction for greenhouse gas emission reductions, we chose a uniform price ascen ding design as being most likely to attract "small" bidders who did not have the resources to work out how to bid correctly in a discriminatory price auction. ${ }^{25}$ And nor, of course, is entry always the key issue. As I discuss further in Klemperer (2002d), good auction design is not "one size fits all", but must always be tailored to its context.

\section{Summary}

Grimm, Riedel and Wolfstetter (2002) have developed an intriguing explanation for the apparently puzzling bidding in the year 2000 German 3G telecom auction. These comments on their paper discuss why I do not find their explanation fully satisfactory, and suggest alternative explanations, including a relative-performance-maximising theory. I also comment briefly on issues about several other $3 \mathrm{G}$ auctions.

22 I emphasised this in Bulow and Klemperer (1996), and Klemperer (1998, 2000, 2002d).

${ }^{23}$ One advantage is identified in note 16: in the German design a bidder might rationally follow a strategy that could mean that it felt sorry to have won as soon as the auction finished.

${ }^{24}$ I was the principal auction theorist advising the Radiocommunications Agency which designed and ran the UK auction. Ken Binmore had a leading role and supervised experiments testing the proposed designs. Other academic advisors ncluded Tilman Börgers, Jeremy Bulow, Philippe Jehiel and Joe Swierzbinski.

${ }^{25}$ Larry Ausubel and Jeremy Bulow were also involved in the implementation of this auction. Strictly this was a descending auction, since the auctioneer was buying reductions in emissions rather than selling permits to emit, but the auction corresponded to an ascending auction to sell emissions. 


\section{References}

Abbink, K., B. Irlenbusch, B. Rockenbach, A. Sadrieh, and R. Selten (2002) The behavioural approach to the strategic analysis of spectrum auctions: the case of the German DCS-1800 auction, Working Paper, Universities of Nottingham, Erfurt, Tilburg, and Bonn.

Binmore, K. and P. Klemperer(2002), The Biggest Auction Ever: the Sale of the British $3 G$ Telecom Licences, Economic Journal, 112 (478), C74-C96, and reproduced with fewer typos at www.paulklemperer.org.

Bulow, J. and P. Klemperer (1996), Auctions vs. Negotiations, American Economic Review 86( 1), 180-194.

Ewerhart, C. and B. Moldovanu (2001), A Stylized Model of the German UMTS Auction, Working Paper, University of Mannheim, Germany.

Grimm, V., F. Riedel, and E. Wolfstetter(2002), The Third Generation (UMTS)Spectrum Auction in Germany, ifo Studien, 48(1),

Klemperer, $P$. (1998), Auctions with Almost Common Values, European Economic Review $42(3-5), 757-769$.

Klemperer, P. (2000), Why Every Economist Should Learn Some Auction Theory, in: $M$ Dewatripont, L. Hansen, and S. Turnovsky (Eds.), Advances in Economics and conometrics: Invited Lectures to Eighth World Congress of the Econometric Society, Cambridge, UK: Cambridge University Press, and available at www.paulklemperer.org.

Klemperer, P. (2002a), How (Not) to Run Auctions: the European 3G Telecom Auctions, European Economic Review 46 (4-5), 829-845.

Klemperer, P. (2002b), Using and Abusing Economic Theory. 2002 Marshall Lecture to the European Economic Association, forthcoming at www.paulklemperer.org.

Klemperer, P. (2002C), Some observations on the British 3G telecom auction: comments on Börgers and Dustmann, ifo Studien, 48 (1), and at www.paulklemperer.org.

Klemperer, P. (2002d), What Really Matters In Auction Design, Journal of Economic Perspectives 16 (1), 169-189. 
Figure 1: European 2000-2001 3G Mobile Spectrum Auctions

Per-Capita Revenues, by Country $\bigcirc$ (right-hand scale)

(auctions are shown on the dates at which they finished)

Dow Jones European Telecom Stock Price Index (left-hand scale)

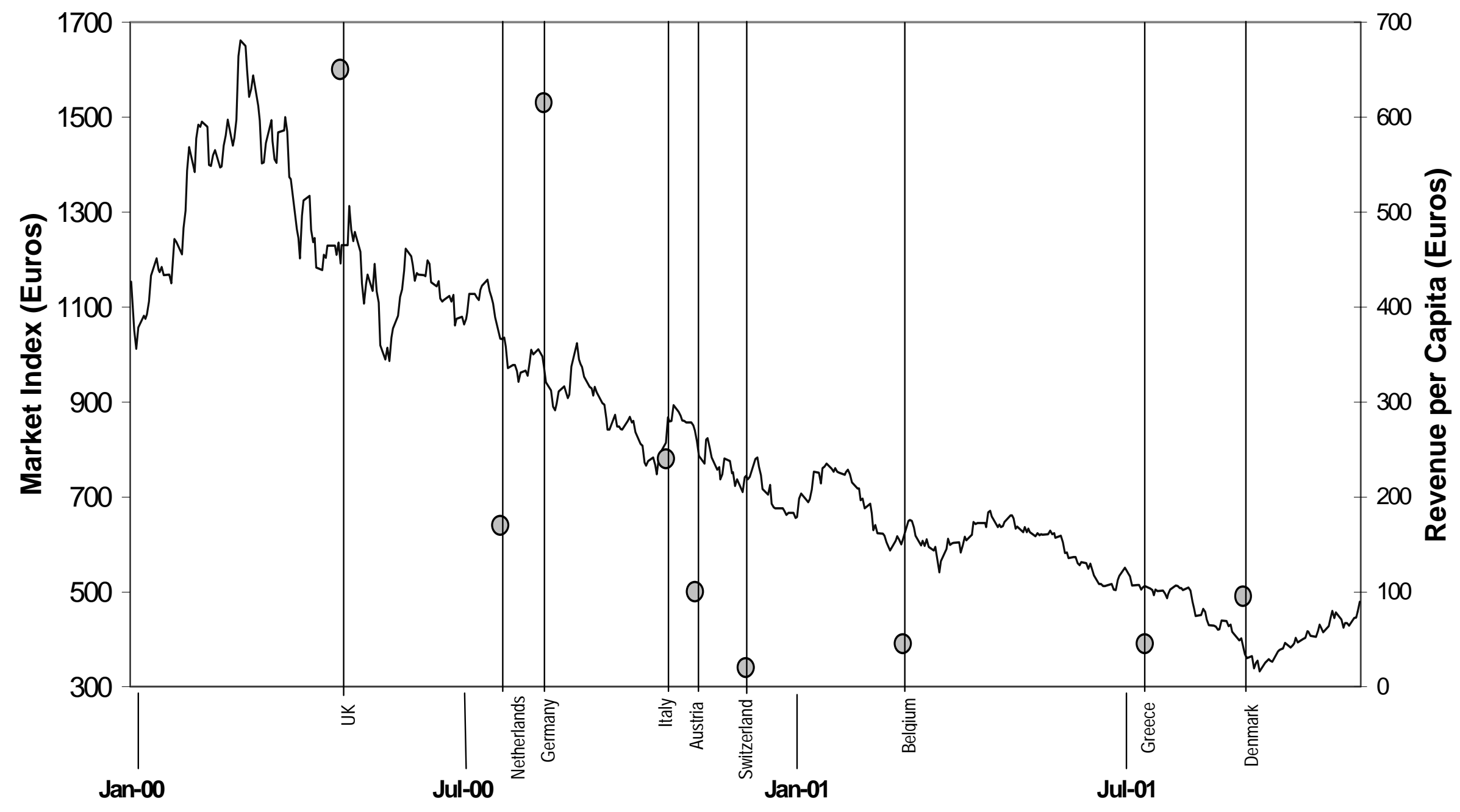


